\title{
Sistem Antrian Berbasis Web Menggunakan Raspberry dan ESP8266
}

\author{
D Jayus Nor Salim ${ }^{1}$, Wisnu Sanjaya ${ }^{2}$, Anton Respati Pamungkas ${ }^{3}$, Agung Koes Indarto ${ }^{4}$ \\ ${ }^{1234}$ Program Studi Sistem Informasi, STMIK AUB, Surakarta, Indonesia \\ e-mail: *1. djayus.nur@stmik-aub.ac.id, ${ }^{2}$ wisnuks1@stmik-aub.ac.id, ${ }^{3}$ anton18@stmik-aub.ac.id, \\ 4agungkoes@gmail.com
}

\begin{abstract}
Abstrak
Salah satu cara meningkatkan kualitas pelayanan pada fasilitas publik yaitu dengan sistem antrian. Metode pengembangan sistem ini adalah model prototyping. Metode ini menekankan pada pencarian model yang sesuai bagi sistem yang akan dikembangkan. Sistem antrian ini menggunakan Arduino Uno (Arduino), NodeMCU ESP8266 (modul WiFi) dan Raspberry Pi 3 (Raspberry). Raspberry berfungsi sebagai server yang dapat menerima request data dari NodeMCU ESP8266 yang terdapat pada konsol atau display melalui jaringan wifi. Untuk menampilkan antrian pada loket display LED P10, digunakan Arduino Uno sebagai mikrokontroler yang menerima data dari NodeMCU ESP8266. Penelitian ini menghasilkan sebuah mesin antrian yang praktis, mudah digunakan dan bersifat portable.
\end{abstract}

Kata kunci: Mesin Antrian, Mikrokontroler, ESP8266, Arduino Uno, Raspberry Pi 3

\section{PENDAHULUAN}

Antrian menjadi kendala pada bagian customer service dalam memberikan pelayanan. Kendala pada kurang teraturnya pelayanan akan berdampak pada ketidakpuasan pelanggan. Sistem antrian merupakan salah satu cara untuk meningkatkan kepuasan pelanggan. Pelayanan terbaik tersebut diantaranya adalah memberikan pelayanan yang cepat sehingga pengguna layanan tidak dibiarkan menunggu terlalu lama. Sistem antrian yang dipakai sebelumnya menggunakan komputer sebagai server dan sebagai client, belum terdapat perangkat praktis seperti konsol dan display LED P10. Sistem ini masih mempunyai banyak kekurangan seperti halnya harus membutuhkan komputer sebanyak loket yang ada dan konfigurasi jaringan. Sistem antrian yang diharapkan merupakan sebuah sistem yang menggunakan Arduino Uno (Arduino), NodeMCU ESP8266 (modul WiFi) dan Raspberry Pi 3 (Raspberry). Raspberry itu sendiri (yang menjalankan sistem operasi Raspbian) berfungsi sebagai server yang dapat menerima request data dari NodeMCU ESP8266 yang terdapat pada konsol atau display melalui jaringan wifi. Untuk menampilkan antrian pada loket display LED P10, digunakan Arduino Uno sebagai mikrokontroler yang menerima data dari NodeMCU ESP8266. Seluruh perangkat keras dan perangkat lunak yang digunakan dalam sistem antrian tersebut adalah berlisensi Open Source. Sehingga hal ini tidak memunculkan isu legalitas dan mengurangi biaya keseluruhan dalam rancang bangun sistem.

\section{METODE PENELITIAN}

Penelitian ini dilakukan dengan menggunakan metode penelitian pengembangan dari sistem yang telah ada sebelumnya dengan menambahkan beberapa perbaikan dan nilai tambah. 2. 1 Analisis dan Kebutuhan Sistem

Analisis kebutuhan sistem dilakukan untuk memahami dengan sebenar-benarnya 
kebutuhan dari sistem dengan mengembangkan sebuah sistem yang mewadahi kebutuhan tersebut. Analisis kebutuhan sistem dibagi menjadi dua tipe kebutuhan sistem, yaitu analisis kebutuhan fungsional (Functional Requirement) dan analisis kebutuhan non-fungsional (NonFunctional Requirement).

\subsubsection{Analisis Kebutuhan Fungsional}

Analisis kebutuhan fungsional pada pengembangan mesin antrian dibagi berdasarkan actor. Actor yang pertama adalah system. Sistem dapat mengelola perangkat yang berupa konsol dan display. Sistem dapat menampilkan nomor dan loket yang berjalan. Sistem dapat menampilkan tombol unutk mengambil nomer antrian. Actor yang kedua adalah perangkat NodeMCU ESP8266 yang terdapat pada konsol. Konsol dapat mengirim dan merespon perintah yang dikirim perangkat NodeMCU ESP8266. Perangkat NodeMCU ESP8266 yang terdapat pada Display dapat merespon dan meneruskan pengirimian data yang diterima dari Raspberry Pi ke Arduino Uno. Arduino Uno yang terdapat pada Display dapat meneruskan data yang dikirim dari NodeMCU ESP8266 yang terdapat pada display ke layar LED P10.

\subsubsection{Analisis Kebutuhan non-Fungsional}

Analisis kebutuhan non-fungsional meliputi dua aspek, yaitu perangkat lunak dan perangkat keras. Perancangan Diagram Blok Sistem menjelaskan keterkaitan antar komponen sistem. Pada penelitian ini alat yang dibangun menggunakan teknologi Internet of Thing (IoT). Jadi perangkat keras mikrokontroler dan alat kontrol yang berupa konsol harus terhubung dengan wifi agar kedua perangkat tersebut berjalan sesuai dengan rancangan. Diagram blok sistem dapat dilihat pada gambar 1.

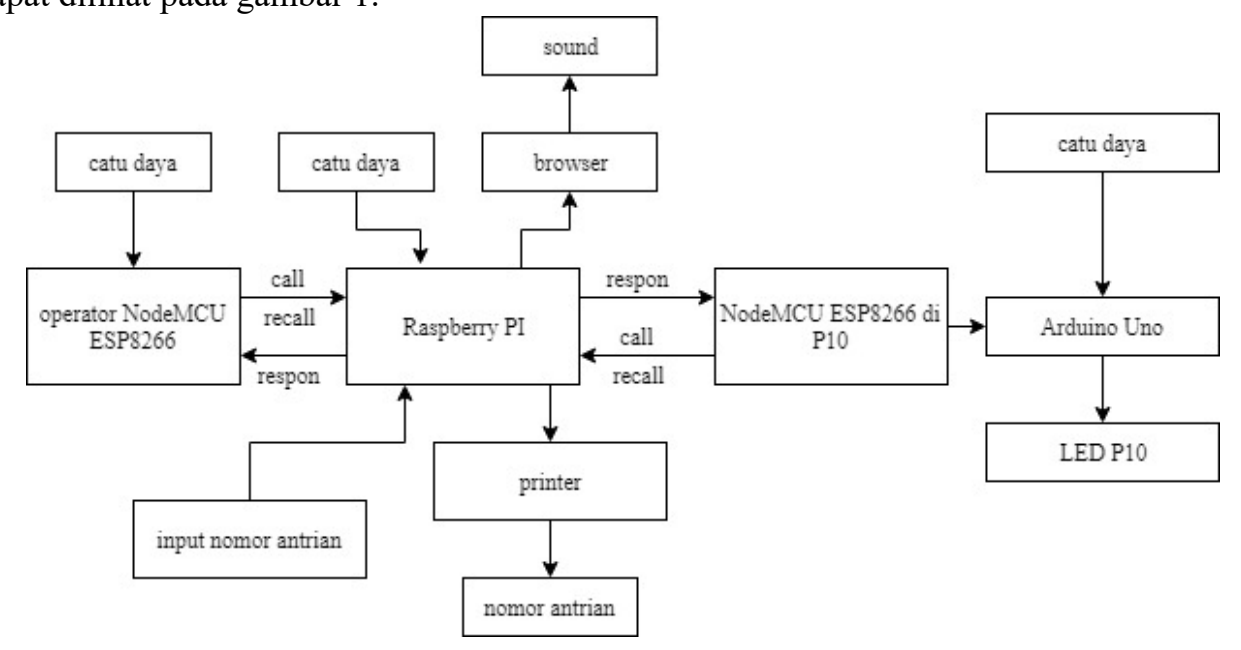

Gambar 1 Diagram Blok Sistem

\section{2 Perancangan Diagram Use Case}

Diagram use case digunakan untuk mempermudah analisis kebutuhan sistem sehingga dapat mengetahui fungsi apa saja yang ada di dalam sistem yang akan dibangun dan menunjukkan bagaimana sistem tersebut berinteraksi dengan user. Gambar yang menunjukkan diagram use case ditunjukkan pada gambar 2 : 


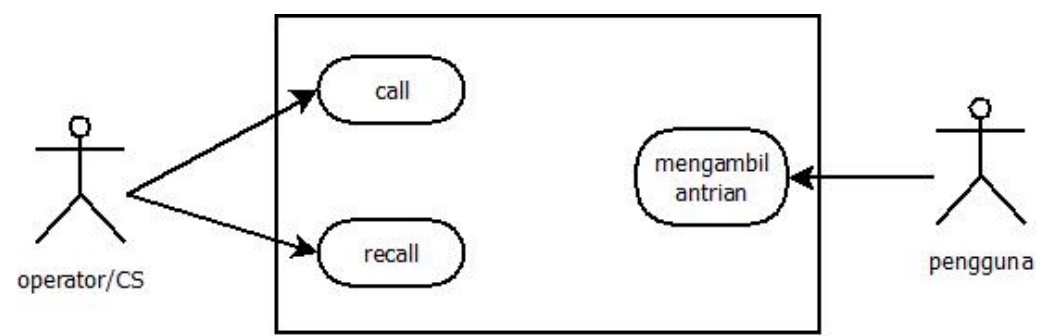

Gambar 2 Diagram Use Case

Berdasakan diagram di atas, dapat disimpulkan bahwa sistem yang akan dikembangkan memeliki dua aktor yaitu operator dan pengguna. Operator bertugas memanggil dan memanggil ulang pengantri. Sedangkan, pengguna hanya dapat mengambil nomer antrian.

\subsubsection{Perancangan Diagram Aktivitas}

Aliran kegiatan yang terjadi pada sistem antrian dapat digambarkan dalam diagram aktivitas. Diagram aktifitas menunjukkan bagaimana aliran kerja (workflow) dari operasi sistem mesin antrian yang akan dikembangkan. Diagram aktivitas ditunjukkan pada gambar 3 dan gambar 4:

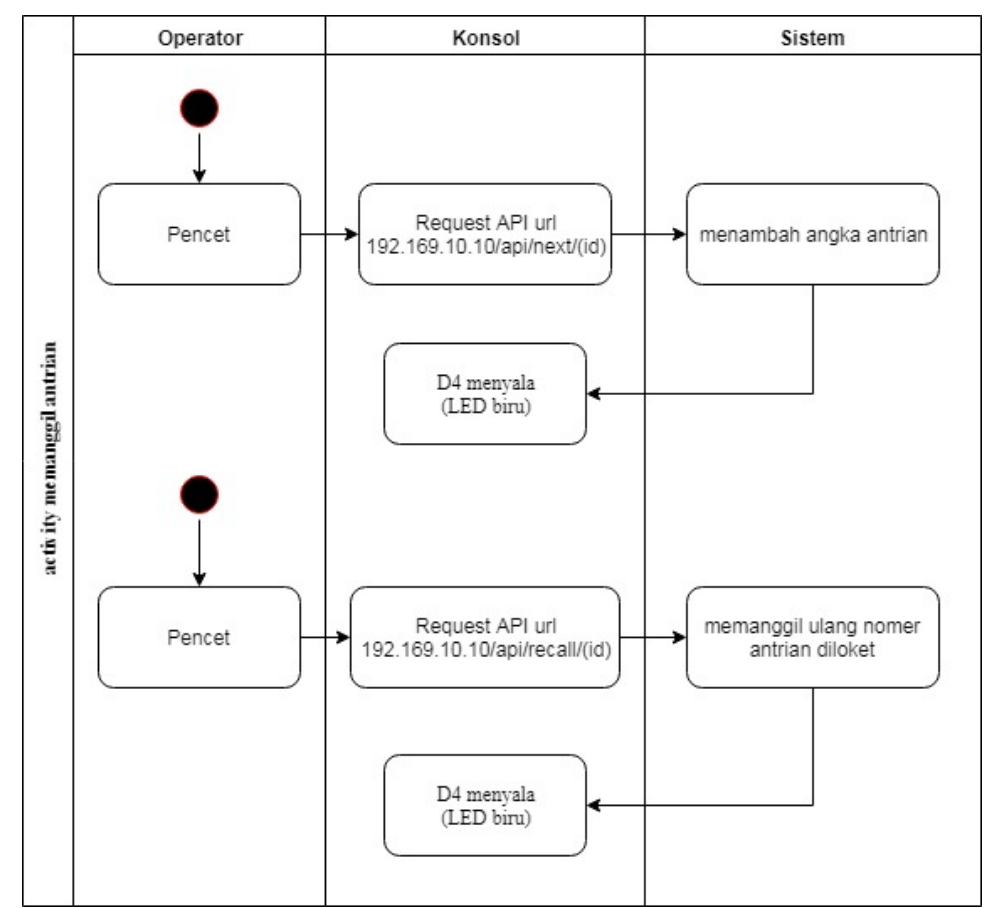

Gambar 3 Diagram Aktivitas Operator 


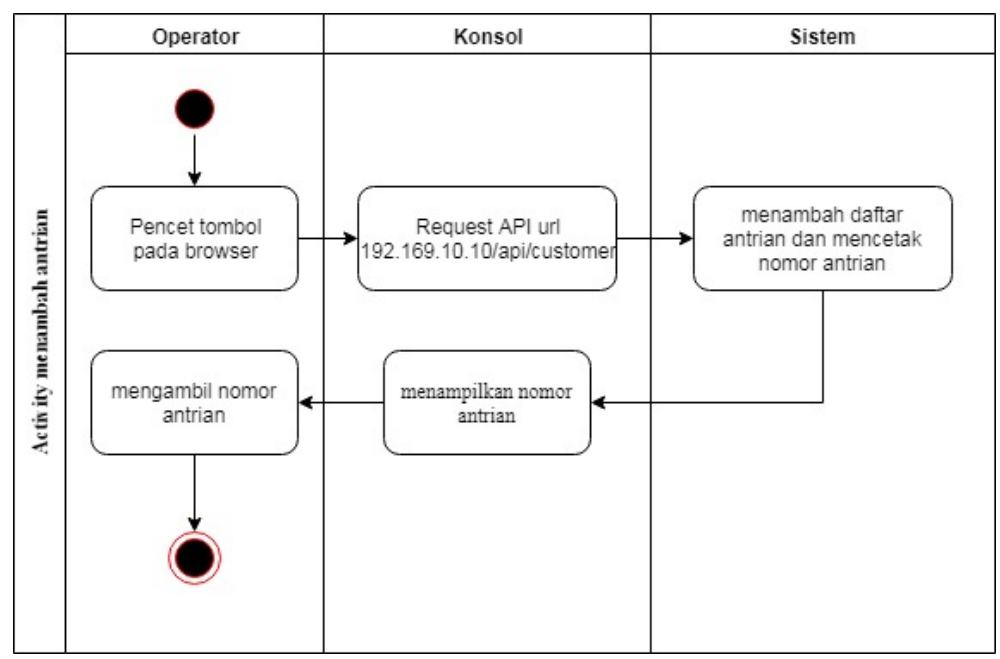

Gambar 4 Diagram Aktifitas Pengguna

\subsubsection{Perancangan Sequence Diagram}

Perancangan sequence diagram dibuat untuk memodelkan urutan dari sebuah proses bisnis sistem antrian. Perancangan sequence diagram dalam penelitian ini dibuat menjadi tiga diagram, dua diagram sequence menggambarkan bagaimana perangkat yang digunakan operator mengirim data ke Raspberry Pi dan bagaimana pengguna menggunakan mesin antrian. Diagram sequence dari pengembangan sistem antrian ini dapat dilihat dari gambar 5 dan gambar 6 :

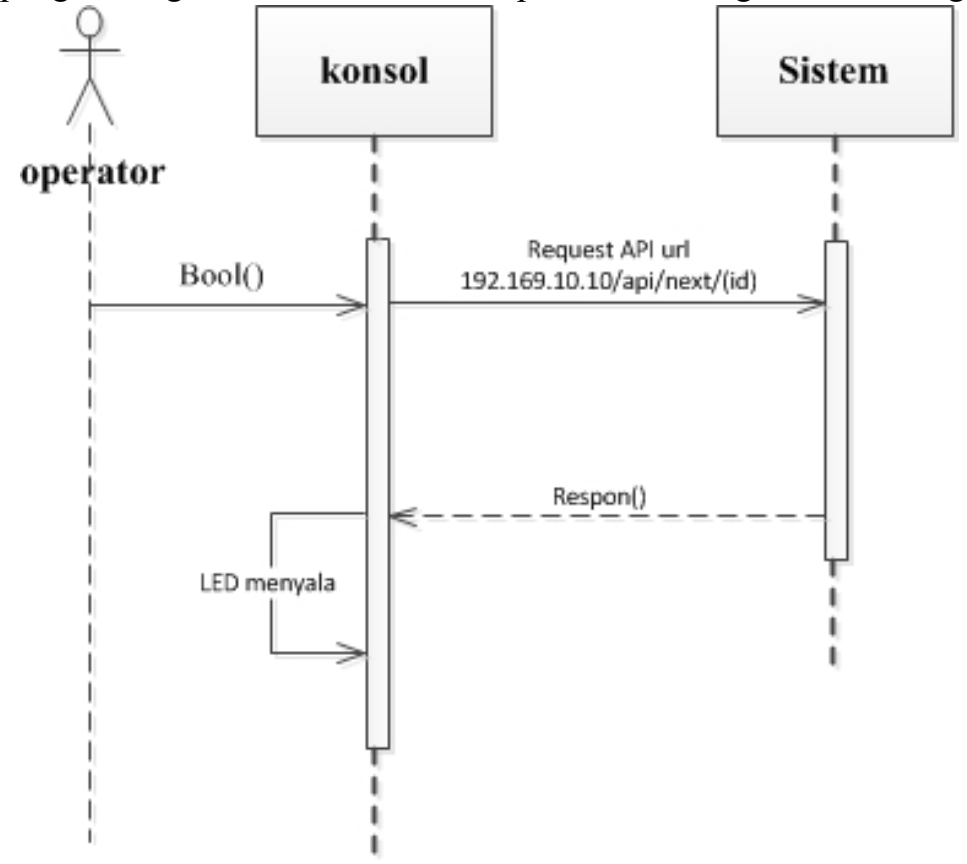

Gambar 5 Sequence Diagram dari Operator 


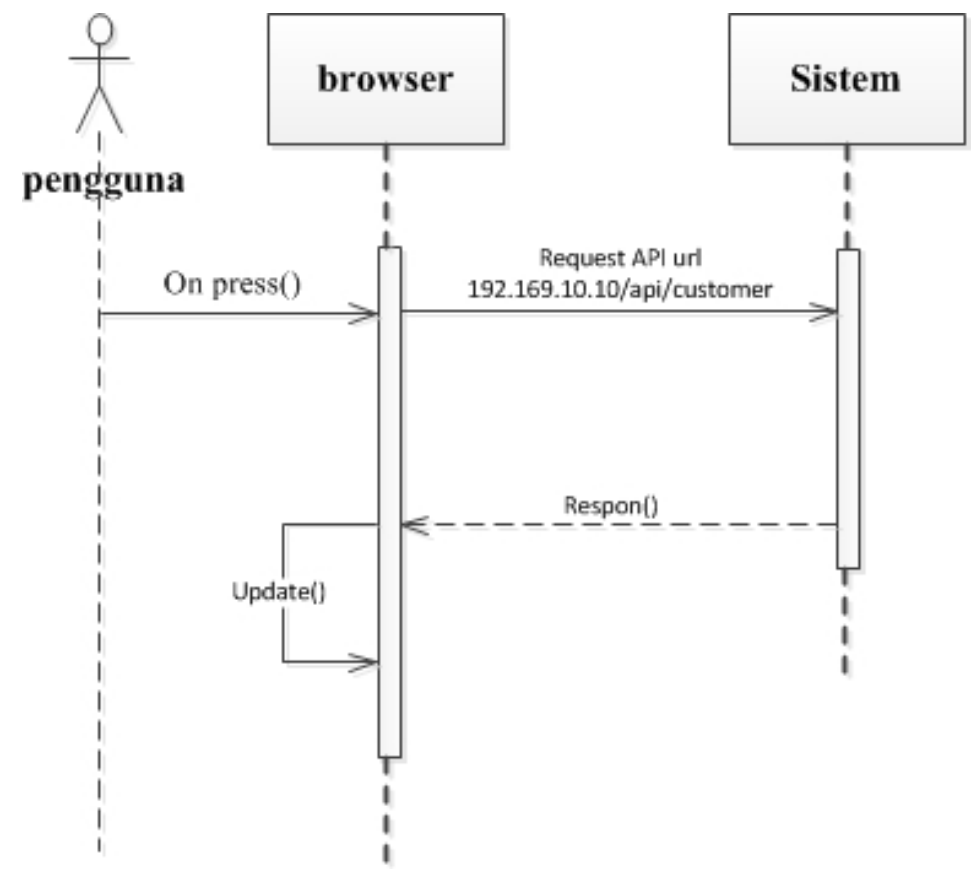

Gambar 6 Sequence Diagram dari Pengguna

\section{HASIL DAN PEMBAHASAN}

\subsection{Pengembangan Perangkat Keras}

\subsubsection{Perangkat Input}

Perangkat input yang digunakan dalam mesin antrian yaitu berupa konsol. Merupakan alat untuk mengirimkan data menggunakan nodeMCU ESP8266 menuju Raspberry Pi dan menerima respon dari Raspberry Pi.

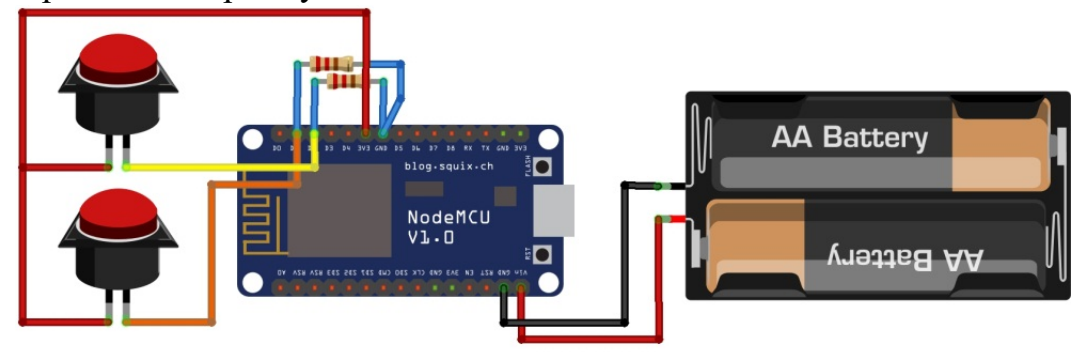

Gambar 7 Rangkaian konsol

fritzing

\subsubsection{Perangakat Output}

Perangkat output berupa Layar LED P10 untuk menampilkan loket dan nomer antrian dengan tambahan perangkat NodeMCU ESP8266 dan mikrokontroler Arduino Uno. 


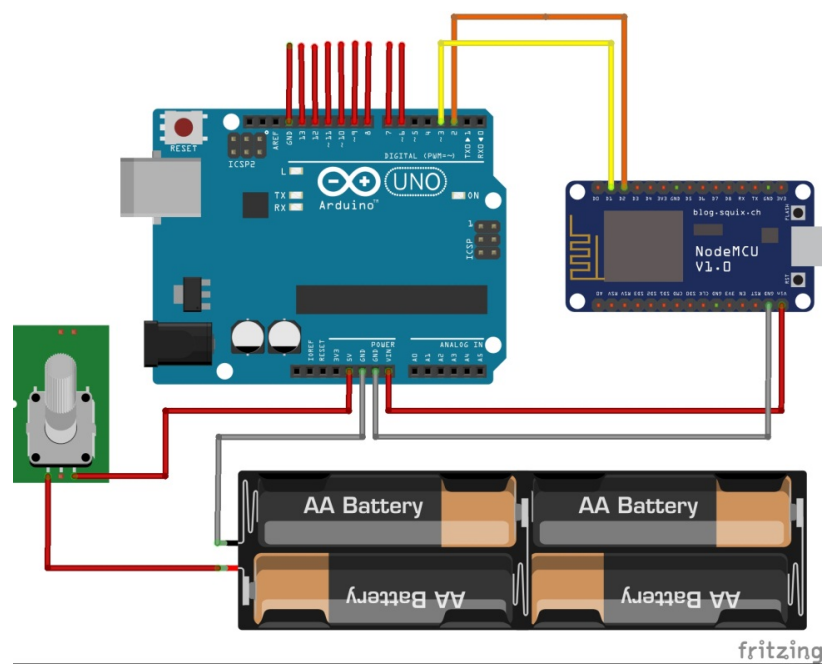

Gambar 8 Rangkaian output ke layar LED P10

\subsection{Pengembangan Perangkat Lunak}

Beberapa tahapan dalam mengembangkan perangkat lunak meliputi: persiapan perangkat, konfigurasi jaringan konsol dan Layar LED P10, pengembangan API, dan pengembangan aplikasi berbasis web.

\subsubsection{Persiapan Sistem}

1. Mempersiapkan dan memformat kartu Mikro SD

2. Melakukan Instalasi Sistem Operasi pada Raspberry

3. Mengatur Koneksi SSH

4. Menginstal Dekstop di Raspberry untuk melihat tampilan raspi.

5. Memperluas Memori Penyimpanan (Storage Memory Expansion) untuk memaksimalkan penggunaan memori penyimpanan di raspberry.

6. Mengatur Waktu dan Tanggal

7. Mengatur RTC

Dikarenakan Raspberry tidak bisa menyimpan settingan waktu secara real time apabila tidak ada catu daya yang masuk, maka menambahkan modul RTC yang dipasangkan pada RTC (Real time clock) adalah jam elektronik berupa chip yang dapat menghitung waktu (mulai detik hingga tahun) dengan akurat dan menjaga/menyimpan data waktu tersebut secara real time. Karena jam tersebut bekerja real time, maka setelah proses hitung waktu dilakukan output datanya langsung disimpan.

\subsection{Pengembangan Jaringan}

Pengembangan jaringan dperlukan untuk pengaturan jaringan Nirkabel (Wifi). Jaringan nirkabel akan digunakan sebagai penghubung antara konsol dan display P10. Oleh karena itu jaringan nirkabel diatur sebagai hotspot atau access point.

\subsection{Pengembangan Application Programming Interface (API)}

Pengembangan Application Programming Interface (API) menggunakan bahasa pemrograman javascript berbasis server yaitu Node.js. API dibangun untuk menghubungkan komunikasi data antara Raspberry Pi, Konsol dan display.

\subsection{Pengembangan Sistem NodeMCU ESP8266 dan Arduino Uno}

Pengembangan sistem di ESP maupun di Arduino Uno, menggunakan bahasa pembrograman $\mathrm{C}++$ yang melalui Aduino IDE,

\subsubsection{NodeMCU ESP 8266}

Pengembangan pada NodeMCU ESP8266 sebenarnya menggunakan bahasa LUA, akan tetapi Mikrokontroler tersebut dapat dijalankan menggunakan bahasa $\mathrm{C}$ yang dikompilasi dengan menggunakan Arduino IDE. Dalam tahapan ini, pengembangan sistem di NodeMCU ESP8266 
dibagi menjadi dua bagian, yaitu NodeMCU yang digunakan di Konsol dan NodeMCU yang digunakan di LED P10.

a. NodeMCU ESP8266 konsol

b. NodeMCU ESP8266 P10

\subsubsection{Arduino Uno}

Pengembangan sistem di Arduino Uno dikembangan menggunakan bahasa $\mathrm{C}++$ melalui aplikasi Arduino IDE.

3.6 Pengembangan Aplikasi Berbasis Web

Aplikasi untuk customer berbasis web dibangun menggunakan bahasa pemrograman Javascript dan didukung HTML dan CSS menggunakan semantic-UI untuk tampilannya. Pada aplikasi ini terdapat tampilan nomer antrian pada loket tertentu dan output suara nomer antrian.

3.7 Implementasi Sistem

Implementasi sistem merupakan suatu proses untuk menempatkan dan menerapkan informasi baru kedalam operasi (Whitten, Bentley \& Barlow : 1993). Maka dari itu dalam tahapan ini penulis melakukan penerapan sistem kedalam bagian - bagian yang sudah direncanakan sebelum siap digunakan. Pada penelitian ini implementasi sistem mesin antrian dibagi menjadi dua bagian. Bagian pertama adalah implementasi perangkat keras yang meliputi mikrokontroler Arduino Uno dan NodeMCU ESP8266 pada Layar LED P10 sebagai perangkat output, NodeMCU ESP8266 pada perangkat konsol sebagai perangkat input. Sedangkan bagian kedua adalah implementasi perangkat lunak yang meliputi perangkat lunak mikrokontroler dan perangkat lunak sistem berbasis WEB.

\subsubsection{Perangkat Input}

Perangkat input diimplementasikan dengan cara menambahkan push up button pada mikrokontroler NodeMCU ESP8266 sebagai tombol call dan recall. Yang diambil dari pin D1 dan pin D2 dan menggunakan baterai AA sebagi catu dayanya.

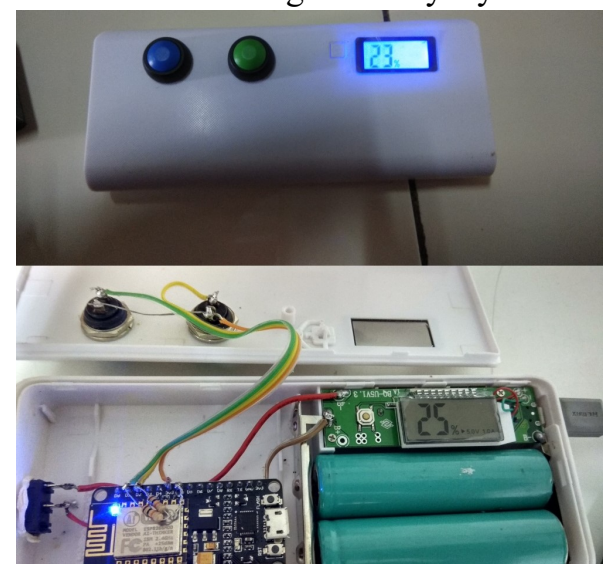

\subsubsection{Perangkat Output}

Gambar 9 perangkat Konsol

Perangkat output diimplementasikan dengan cara menggabungkan antara mikrokontroler NodeMCU ESP8266, Mikrokontroler Arduino Uno dan LED P10. Implementasi output dapat dilihat pada gambar 10. 


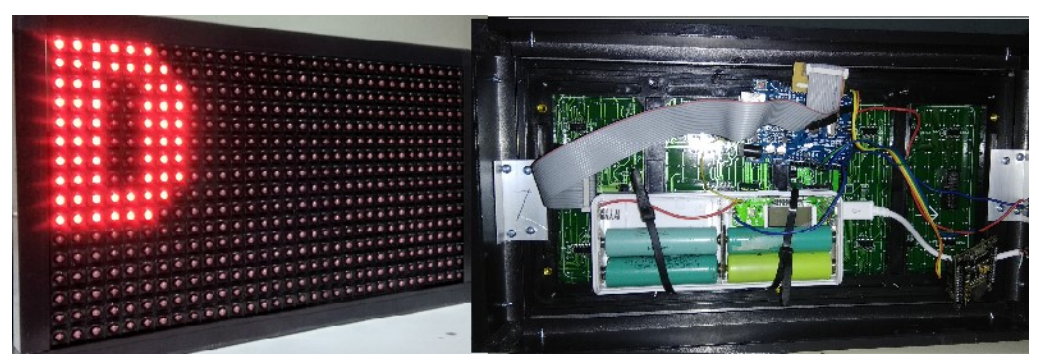

Gambar 10 Layar LED P10

\subsubsection{Perangkat Lunak Mikrokontroler}

Perangkat lunak mikrokontroler mikrokontroler Arduino Uno dan mikrokontroler NodeMCU ESP8266 diprogram menggunakan software Arduino IDE. NodeMCU ESP8266 yang terdapat di konsol berfungsi untuk mengirim data ke Raspberry Pi. Sedangkan NodeMCU ESP8266 yang terdapat di layar LED P10 bertugas untuk merequest data dari Raspberry Pi dan diteruskan ke mikrokontroler Arduino Uno. Untuk mikrokontroler Arduino Uno bertugas untuk menampilkan data menuju Layar LED P10.

\subsubsection{Perangkat Lunak berbasis WEB}

Perangkat lunak web dibuat guna untuk menampilkan antrian di setiap loket sehingga pengguna dapat melihat melihat daftar antrian pada salah satu loket. Implementasi perangkat lunak berbasis web dapat dilihat pada gambar 11.

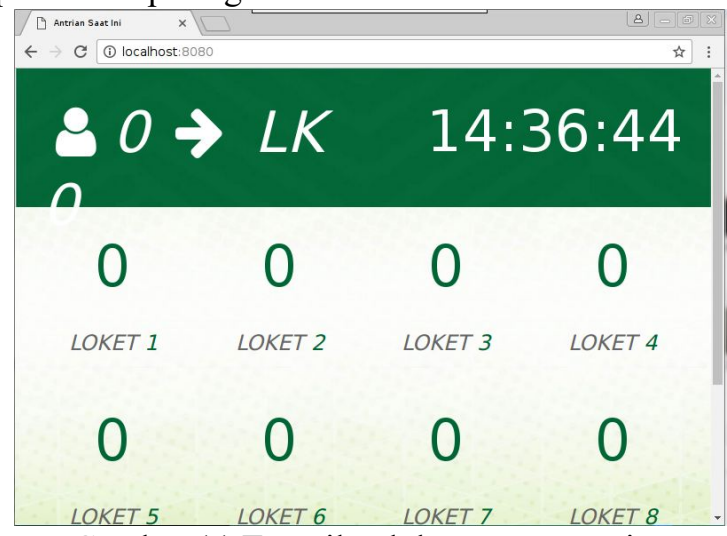

Gambar 11 Tampilan loket nomer antrian

\section{KESIMPULAN}

Raspberry dapat digunakan sebagai server dengan baik. Perangkat endpoint(NodeMCU ESP8266) yang terhubung juga dapat mengirim, menerima dan merespon dengan baik. Mikrokontroler Arduino uno dapat menerima dan meneruskan data dengan baik. Perangkat lunak yang dikembangkan dapat memonitor data antrian. Web Browser Chromium kurang maksimal untuk memutar suara antrian secara bersamaan.

\section{SARAN}

Perlu adanya dashboarb admin untuk mengatur banyaknya loket yang dibuka. Perlu mencari web browser yang lebih kompeten untuk menjalankan suara kekurangan.

\section{DAFTAR PUSTAKA}

[1] Arduino.cc. (n.d.). Arduino UNO \& Genuino UNO. Retrieved Januari 18, 2018, from Arduino.cc: https://www.arduino.cc/en/Main/ArduinoBoardUno. 
[2] Dirakit.com. (n.d.). Mesin Antrian Menggunakan Raspberry Pi + NodeJS. Retrieved Januari 18, 201, from Dirakit: https://dirakit.hackster.io/mfauzanyk/mesin-antrianmenggunakan-raspberry-pi-nodejs-e1a777.

[3] Muhammad Syahwil. (2013). Panduan Mudah Simulasi dan Praktik Mikrokontroler Arduino. Yogyakarta : ANDI

[4] Eko Putra, Agfianto. (2002), Belajar Mikrokontroler AT89S51/52 Teori dan Aplikasi, Edisi ke-1, Yogyakarta, Gava Media.

[5] Budiharto, Widodo \& Gamayel Rizal. 2007. Belajar Sendiri 12 Proyek ikrokontroler Untuk Pemula. Jakarta: PT. Elex Media Komputindo Kelompok Gramedia.

[6] Jogiyanto. 2001. Analisis \& Desain Sistem Informasi : pendekatan terstruktur teori dan praktek aplikasi bisnis. Andi, Yogyakarta.

[7] Gross, D \& Haris, C. M. 2008. Fundamental of Queueing Theory: Fourth edition. John Willey \& Sons, Inc: New Jersey.

[8] Heizer, J. \& Render, B. 2011. Operations Management. Tenth Edition. Pearson, New Jersey, USA.

[9] Siagian, P., 1987, Penelitian Operasional : Teori dan Praktek, Universitas Indonesia Press. Jakarta.

[10] Sholiq. (2006). Pemodelan Sistem Informasi Berorientasi Objek dengan UML, Yogyakarta: Graha Ilmu.

[11] Khadir, A. (2013). From zero to a Pro HTML5. Yogyakarta: Penerbit Andi.

[12] Adi Nugroho. 2010. Rekayasa Perangkat Lunak Berbasis Objek dengan Metode USDP. Penerbit Andi. Jogjakarta.

[13] Tantra, Rudy. (2012). Manajemen Proyek Sistem Informasi. Yogyakarta : ANDI Yogyakarta.

[14] Pressman. Roger S . Rekayasa Perangkat Lunak . Terj. LN Harnaningrum, Yogyakarta : ANDI, 2002.

[15] Ashton, K. (2009, Juni 22). That 'Internet of Things' Thing. Dipetik Januari 19, 2018, dari RFID Journal: http://www.rfidjournal.com/articles/view?4986

[16] Budiharto, Widodo. (2005). Perancangan Sistem dan Aplikasi Mikrokontroller. Jakarta: Erlangga.

[17] Novida Dwi Nurhayati, "Desain dan KonstruksiSistem Antrian dengan Microcontroller ATMega 8535 pada Rumah Sakit". Proyek akhir PENSITS, 2010.

[18] Nilapuspa Fridatama, Anang Budikarso, Mike Yuliana. Rancang Bangun Sistem Layanan Antrian Rumah Sakit Berbasis Java. Surabaya : Institut Teknologi Sepuluh Nopember

[19] Maulany, Raymond. 2016. Perancangan Sistem Informasi Antrian Pendaftaran Pembayaran Uang Kuliah Berbasis Foto Wajah Di Kantor Biro Keuangan Universitas Advent Indonesia. Jurnal, Bandung : Univrsitas Advent Indonesia

GO INFOTECH: JURNAL ILMIAH STMIK AUB Vol. 25, No. 1, Juni 2019 : 62 - 70 